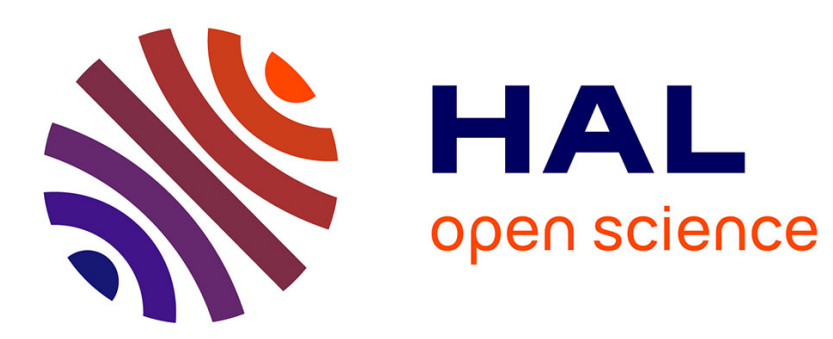

\title{
FINAL FRONTIER GAME: A CASE STUDY ON LEARNER EXPERIENCE
}

Nour El Mawas, Irina Tal, Arghir Nicolae Moldovan, Diana Bogusevschi, Josephine Andrews, Gabriel-Miro Muntean, Cristina Hava Muntean

\section{To cite this version:}

Nour El Mawas, Irina Tal, Arghir Nicolae Moldovan, Diana Bogusevschi, Josephine Andrews, et al.. FINAL FRONTIER GAME: A CASE STUDY ON LEARNER EXPERIENCE. CSEDU - 10th International Conference on Computer Supported Education, Mar 2018, Funchal, Portugal. hal02249338

\section{HAL Id: hal-02249338 \\ https://hal.science/hal-02249338}

Submitted on 1 Aug 2019

HAL is a multi-disciplinary open access archive for the deposit and dissemination of scientific research documents, whether they are published or not. The documents may come from teaching and research institutions in France or abroad, or from public or private research centers.
L'archive ouverte pluridisciplinaire HAL, est destinée au dépôt et à la diffusion de documents scientifiques de niveau recherche, publiés ou non, émanant des établissements d'enseignement et de recherche français ou étrangers, des laboratoires publics ou privés. 


\title{
FINAL FRONTIER GAME: A CASE STUDY ON LEARNER EXPERIENCE
}

\author{
Nour El Mawas ${ }^{1}$, Irina Tal ${ }^{1}$, Arghir Nicolae Moldovan ${ }^{1}$, Diana Bogusevschi $^{2}$, Josephine Andrews ${ }^{1}$, \\ Gabriel-Miro Muntean ${ }^{2}$ and Cristina Hava Muntean ${ }^{1}$ \\ ${ }^{I}$ School of Computing, National College of Ireland, Dublin, Ireland \\ ${ }^{2}$ School of Electronic Engineering, Dublin City University, Dublin, Ireland \\ \{Nour.ElMawas, Irina.Tal, ArghirNicolae.Moldovan\}@ncirl.ie,diana.bogusevschi@dcu.ie, Josephine.Andrews@ncirl.ie, \\ Gabriel.Muntean@dcu.ie,Cristina.Muntean@ncirl.ie
}

Keywords: Technology enhanced Learning, STEM, Educational Video Game, Primary Education, and Solar System.

\begin{abstract}
Teachers are facing many difficulties when trying to improve the motivation, engagement, and learning outcomes of students in Science, Technology, Engineering, and Mathematics (STEM) subjects. Game-based learning helps the students learn in an immersive and engaging environment, attracting them more towards STEM education. This paper introduces a new interactive educational 3D video game called Final Frontier, designed for primary school children. The proposed game design methodology is described and an analysis of a research study conducted in Ireland that investigated learner experience through a survey is presented. Results show that: (1) $92.5 \%$ of students have confirmed that the video game helped them to understand better the characteristics of the planets from the Solar system, and (2) $92.6 \%$ of students enjoyed the game and appreciated different game features, including the combination between fun and learning aspects which exists in the game.
\end{abstract}

\section{INTRODUCTION}

With the advancements in technology and the need to drive engagement and enquiry in STEM subjects, there is an increased usage of game-based learning pedagogy. This technology-based teaching pedagogy is now applied at all levels of education, from primary school to the third level education. In $2015,47 \%$ of K-12 teachers reported that they use game-based learning in their classrooms, and almost $66 \%$ of K-5 teachers mentioned the use of digital games in their curriculum (Doran 2016). Currently increasing number of students are exposed to game-based learning in their formal, non-formal and in-formal education and this trend is expected to continue. For instance, the TechNavio's report published in August 2017 (TechNavio 2017) forecasts that K-12 gamebased learning market is expected to grow at a compound annual growth rate of nearly 28 percent during the period 2017-2021.

Game-based learning involves the use of gaming technology for educative purposes where students explore concepts in a learning context designed by teachers. Game-based learning helps the students learn in an immersive and engaging environment. One aspect that made game-based learning usage so popular is its ability to teach students how to solve complex problems. Simple problems/tasks to be solved are given to the player at the beginning of the game and later on the tasks become progressively more difficult, as the player is progressing in the game and his/her skills and knowledge develop.

The growing importance of Science, Technology, Engineering, Mathematics (STEM) education is also driving the growth of game-based learning market. This is due to the fact that educational games encourage students to get involved in live projects or real-time activities so that they can learn by experimenting (Ravipati 2017). The game-based learning pedagogy also boosts students' confidence in STEM-related subjects, increase their interest in complex topics and helps teachers to deal with disengagement of young people from STEM.

The new 21st century STEM teaching and learning paradigm replaces the old approach in which 
the teacher is the only source of all the knowledge, everyone learns the same way, and the class is the only place in which knowledge is transmitted. The 21 st century teaching and learning paradigm is dynamic, technology-enabled, student-centric and develops $21^{\text {st }}$ century competencies and skills such as digital literacy, communication, collaboration, critical thinking, problem solving, decision making and creativity.

In this context, the use of an educational game creates engaging classrooms in STEM subjects, demystifies the pre-conceived idea among students that science and technologies subjects are difficult, improves learning outcome and increases student motivation and engagement.

The research work reported in this paper is dedicated to STEM community and in particular to researchers, and teachers in primary schools who meet difficulties when engaging students in STEM courses.

The paper presents of a research study on learner experience when a new interactive educational 3D video game called Final Frontier, designed for primary school students, was used in the class. The educational game delivers knowledge on two planets from the Solar system: Mercury and Venus.

The paper is organized as follows. Section 2 proposes the theoretical background of the study and describes some existing educational games related to the Solar system. Section 3 details our scientific positioning, gives an overview of the Final Frontier game and defines the game design methodology. Section 4 presents research methodology of the case study and its results. Section 5 summarizes the paper, draws conclusions regarding the research study performed and presents future perspectives.

\section{RELATED WORK}

Game-based learning (GBL) represents an educational approach that integrates video games with defined learning outcomes. The appeal of using video games in education can be partially explained by the need to reach today's digital learners that have continuous access to entertainment content through the Internet. At the same time, games provide highly engaging activities that are stimulating, generate strong emotions, require complex information processing, provide challenges and can support learning and skill acquisition (Boyle, Connolly, and Hainey, 2011). The learning experiences and outcomes of educational games can be classified into several classes which include: knowledge acquisition, practising and processing (content understanding), knowledge application (skill acquisition), reflection (behaviour change) and knowledge anticipation (motivation outcomes) (Jabbar and Felicia, 2015).

Previous research works have shown that gamebased learning can have positive effects on important educational factors such as student motivation and engagement (Ghergulescu and Muntean, 2012, Ghergulescu and Muntean, 2010a), learning effectiveness (Erhel and Jamet, 2013), as well as learning attitude, achievement and self-efficacy (Sung and Hwang, 2013, Ghergulescu and Muntean, 2016). Moreover, game-based learning has the potential to facilitate the acquisition of $21^{\text {st }}$ century skills such as critical thinking, collaboration, creativity and communication (Qian and Clark, 2016). While there is much research evidence of GBL benefits, some studies failed to reproduce them or obtained contradictory findings. Tobias et al., argue that this may be due to lack of design processes that effectively integrate the motivational aspects of games with good instructional design to ensure learners acquire the expected knowledge and skills (Tobias, Fletcher, and Wind, 2014). The authors also made recommendations for educational game design, such as to provide guidance, use first person in dialogues, use animated agents in the interaction with players, use human rather than synthetic voices, maximise user involvement and motivation, reduce cognitive load, integrate games with instructional objectives and other instruction, use teams to develop instructional games (Tobias et al., 2014).

One common criticism of game-based learning studies is that they lack foundation in established learning theories. A meta-analysis of 658 game-based learning research studies published over 4 decades, showed that the wide majority of studies failed to use a learning theory foundation $(\mathrm{Wu}, \mathrm{Hsiao}, \mathrm{Wu}, \mathrm{Lin}$, and Huang, 2012). Among the studies that had a pedagogical foundation, constructivism appears to be the most commonly used as indicated by multiple review papers (Li and Tsai, 2013; Qian and Clark, 2016; Wu et al., 2012). Other learning theories that were also implemented by different research studies include: cognitivism, humanism and behaviourism. Common learning principles employed by gamebased learning studies include among others: experiential learning, situated learning, problembased learning, direct instruction, activity theory, and discovery learning (Wu et al., 2012).

Few studies have proposed and/or evaluated educational games related to planets or the solar system (Muntean and Andrews, 2017). HelloPlanet is a game where the player can observe and interact with 
a planet that has a dynamic ecosystem, where the player can simulate organisms, non-organisms, terrains, and more (Sin et al., 2017). The game evaluation results from 41 primary and secondary school children, showed a statistically significant learning gain for both girls and boys, and an effect on interest in STEM for girls, but not for boys. The Space Rift game enables students to explore the Solar system in a virtual reality environment (Peña and Tobias, 2014). However, the game evaluation involved only 5 students and was mostly focused on usability rather than educational aspects. The Ice Flows game aims to educate the users about the environmental factors such as temperature and snowfall on the behaviour of the Antarctic ice sheet (Le Brocq, 2017). However, the game was either not evaluated or the results were not published yet.

A recent systematic review of game-based learning in primary education has indicated that games were used to teach a variety of subjects, among which the most popular being Mathematics, Science, Languages and Social Studies (Hainey et al., 2016). However, the review authors also concluded that more research studies are needed to evaluate the pedagogical benefits of GBL at primary level.

In this context, our research contributions are as follows: (i) proposal of an extended educational games design methodology, (ii) development of the Final Frontier educational game for teaching Solar system planets-related concepts, a topic that was not thoroughly covered by previous research studies, and (iii) evaluation of the game benefits when deployed to target primary school students.

\section{THE FINAL FRONTIER GAME}

\subsection{Game Description}

Final Frontier is an interactive 3D educational video game about space for children up to 12 years old. The game supports knowledge acquisition on Solar system planets (i.e. Mercury and Venus were targeted in this study) through direct experience, challenges and fun. The topics coved by the game are part of the Geography curriculum, section "Planet Earth and Space", defined for the primary school in Ireland. The game has different levels, each level containing different models and landscapes. In each level, the game requires meeting a game objective (i.e. mission), collection of stars and meteorites and has constrains e.g. coolant time. Information regarding the number of stars and meteorites collected, coolant time and game level mission is displayed on the screen.

Once a level is completed, the player must answer correctly a multi-choice question in order to be able to progress to the next level. The player is allowed to try to answer the question multiple times if a wrong answer is provided.

The game starts by bringing the player on a spaceship where he game mission is explained. There are two activities that the player has to complete during the first activity, the player is instructed to visit the first planet, Mercury. The game goal related to this planet is to explore the environment and to collect five meteorites hidden in the craters that exist on Mercury (see Figure 1). The player may use the jetpack to get in and out of the craters. An avatar provides extra information (facts) about the planet during the play time.

Figure 2 illustrates how the level mission as well as the number of meteorites and stars a player has collected are displayed on the screen for the entire duration of playing a level.

Once the mission on Mercury was completed, the player returns to the spaceship, in the puzzle room where he/she must answer a question (e.g. What is the closest planet to the Sun?).

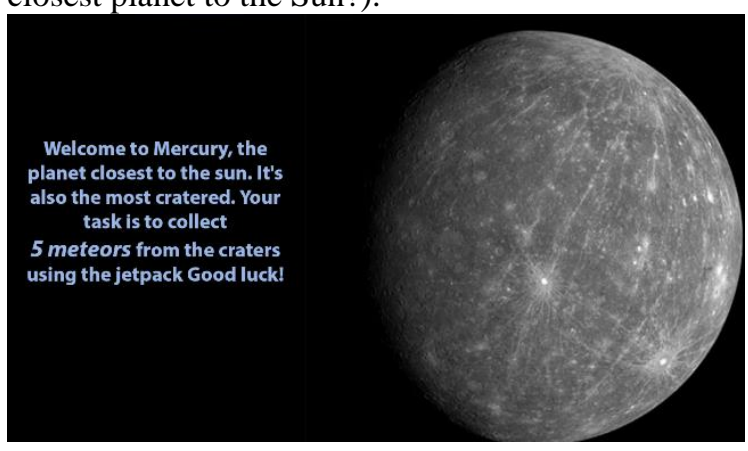

Figure 1: The goal of the mission to Mercury.

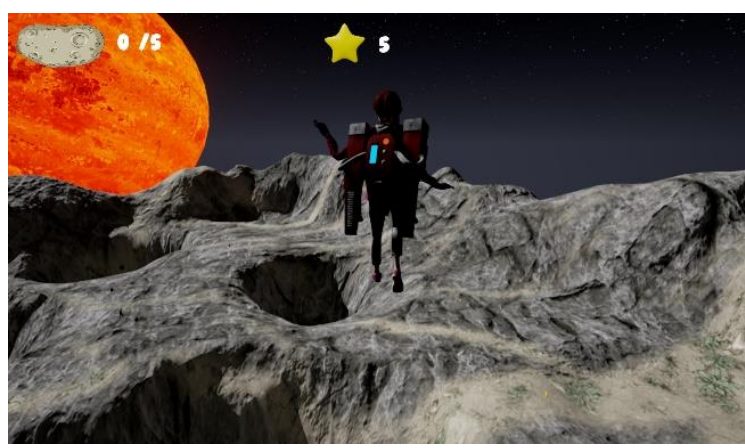

Figure 2: The player using jetpack on Mercury. 


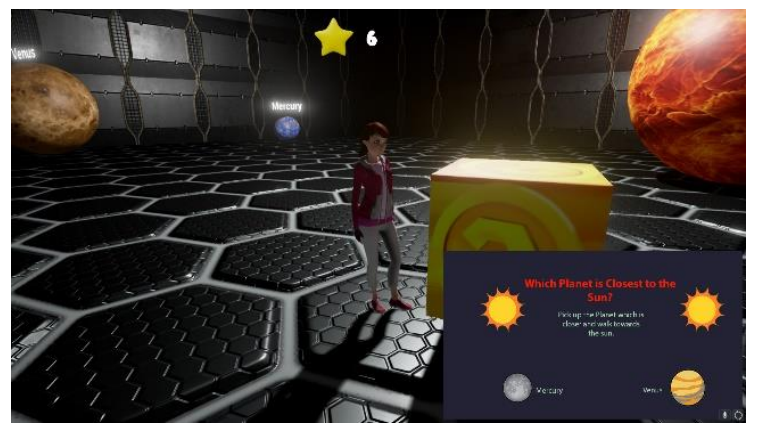

Figure 3: Puzzle room and the question about Mercury.

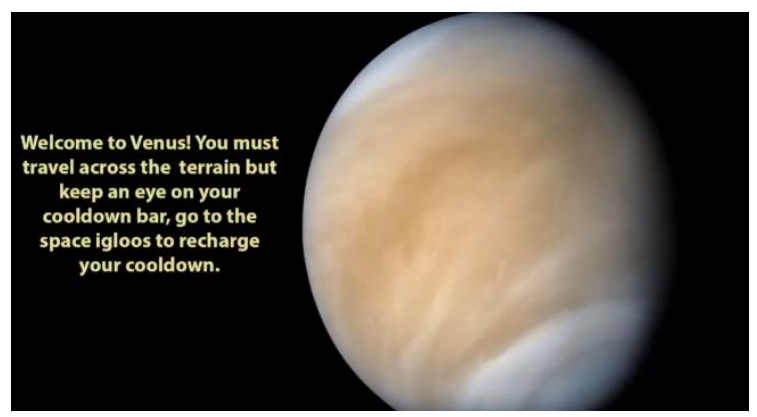

Figure 4: The objective of the mission to Venus.

A screenshot of this game activity is presented in Figure 3. The aim of this mini quiz is to check player's knowledge about Mercury. The player interacts with the game environment when answering the question by picking up the correct object (e.g. planet Mercury) and placing it beside the Sun.

Once this question is answered correctly, the player is awarded a key that is used to open a door on the spaceship and progress to the next level.

The second level is associated with another activity which requires the player to explore the planet Venus and complete a given task. The mission is to traverse the Venus environment without letting their cooldown bar get to zero. Buildings called igloos may be used to recharge their coolant supply (see Figure 4).

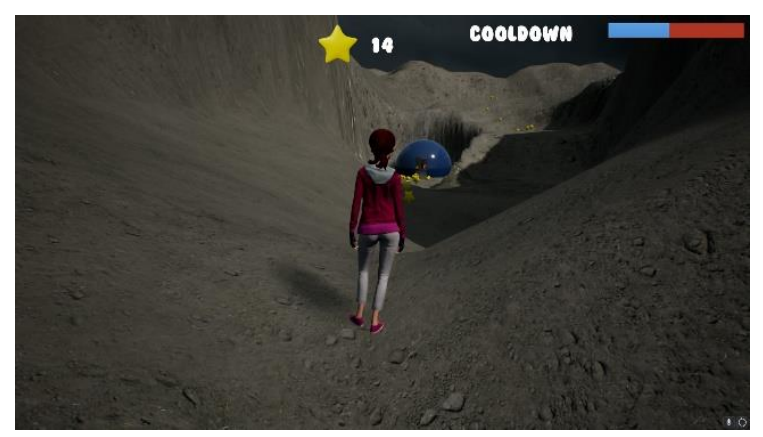

Figure 5: The player on Venus planet.

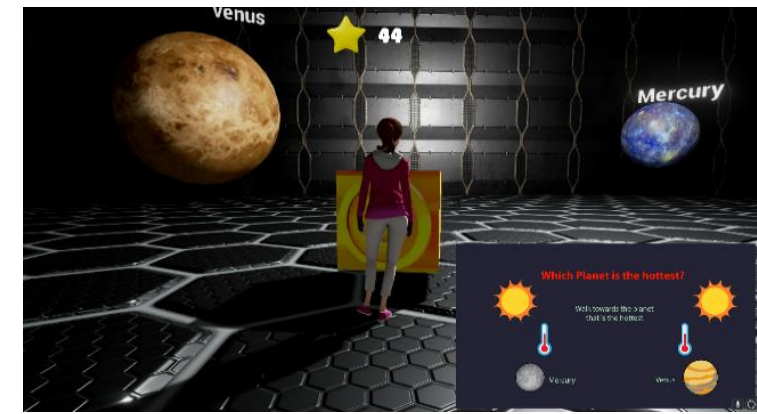

Figure 6: Puzzle room and the question about Venus.

Next, the player is teleported to the Venus planet surface. There are four buildings (igloos) that the player may enter while crossing the terrain. The cooldown bar depletes when traversing the planet surface, which is very hot (Figure 5), but regenerates when the player enters any of the buildings. While traversing the terrain, the player may collect stars that are added up to the overall stars score. Facts about Venus are displayed during the play time.

Once the player reaches the fourth igloo, he/she is returned to the spaceship, into the puzzle room and asked to complete the second puzzle. A multi-choice question about Venus (see Figure 6) must be answered correctly in order to complete this level.

The puzzle asks the player to identify which planet is the hottest in the Solar system. Three planets are displayed. The player must walk towards the planet that represents the correct answer. Once this is done the game is complete. The overall number of collected starts is also displayed.

\subsection{Game Design Methodology}

The methodology for designing the Final Frontier game is based on that described in (Marfisi et al., 2010). However, two steps related to the learning puzzle such as the general description of the learning puzzle and detailed description of the learning puzzle were added.

Table 1: LOs of the Final Frontier game.

\begin{tabular}{|c|c|}
\hline Planet & LOs \\
\hline Mercury & $\begin{array}{c}\text { - Closest planet to the sun (LO1) } \\
\text { - Planet with the most craters (LO2) } \\
\text { - Smallest planet (LO3) }\end{array}$ \\
\hline Venus & $\begin{array}{c}\text { - Hottest planet due to the greenhouse } \\
\text { effect (LO1) } \\
\text { - Spins opposite direction to Earth } \\
\text { (LO2) }\end{array}$ \\
& $\begin{array}{c}\text { - High Gravity cannot jump very high } \\
\text { (LO3) }\end{array}$ \\
\hline
\end{tabular}


The authors believe that recall is a very important step in the learning process. Moreover, the recommendations on efficient game design proposed by (Tobias et al., 2014) were taken into account.

The game design methodology proposed in this research is composed of the following steps:

- $\quad$ specification of the pedagogical objectives,

- choice of the game model,

- general description of the scenario and virtual environment,

- general description of the learning puzzle,

- choice of a software development engine,

- detailed description of the scenario,

- detailed description of the learning puzzle,

- $\quad$ pedagogical quality control, and

- game distribution.

Specification of the pedagogical objectives: the proposed 3D interactive educational game shall be used to teach concepts on the solar system in primary schools. The first step of the conception phase consists of defining the concepts that must be learned by the students. For this reason, the authors worked with teachers from European primary schools that teach the Geography subject to make sure that the designed game covers the required topics specified in the curriculum. The pedagogical objectives of the game were defined and presented in Table 1.

Choice of the game model: Once the pedagogical objectives were defined, Adventure was selected as the game model for the Final Frontier. The Adventure game model involves the player assuming the role of the protagonist in the game, exploring the environment and completion of puzzles in order to progress. Collectable objects such as stars and meteorites are also included. The jetpack allows the player to go higher than the jump. The puzzle embedded in the game requires the player to complete various tasks in order to progress through the game. The collectable stars are used to guide the player and encourage him/her to explore the environment. The meteorites are used on the Mercury planet as a collectable to gauge the players' progress. The cooldown feature is used on Venus and gives the player a challenge, as they go through the level.

The game design has considered three areas: the spaceship where the game starts and finishes and where the player goes back to after visiting a planet; planet Mercury which the player visits during the first activity; and planet Venus that hosts the second activity to be completed.

The Adventure game model is one of the most popular among children. The children get more immersed and motivated when they play adventure games over other types. Moreover, the Adventure game model involves a linear story that can be easily defined in the game. Various gameplay features such as jetpack, puzzle solving, collectable stars and meteorites, cooldown bar were also defined in this game mode.

General description of the scenario and virtual environment: the aim of this part is to structure the pedagogical scenario and match it up with a fun based scenario. The main focus was to make the game familiar to the learners. The characters are simple human characters so the player can easily interact with. The story of the game is that the player is on a field trip, and he/she visits some planets. The player is assigned a task to do on each planet and learns implicitly facts about the planet while playing.

General description of the learning puzzle: When the player completes a given task, he/she is brought back to the spaceship to solve a puzzle and when successful, to progress to the next level. The puzzle learning was added because it was believed that active recall is a principle of efficient learning. Many studies demonstrate the role of active recall in consolidating long-term memory e.g. (Spitz, 1973).

Choice of a software development engine: concerning the game development engine, Unreal Engine 4 or Unity, two of the most popular game development engines, can be used. Unreal Engine 4 was used in this game development due to its graphic potential, especially as it was aimed to give to the player the most realistic environment of the planets.

Detailed description of the scenario: this step involves the illustration of each scene with all the details and interactions to be integrated into the game.

Detailed description of the learning puzzle: the game has two puzzles that correspond to the two planets. Once the puzzle is answered correctly the player is allowed to go to the next planet. The player is allowed to try to answer the puzzle multiple times if a wrong answer was given.

Pedagogical quality control: the developed game was shown to the teacher to validate it and to approve the pedagogical quality of the game. Feedback was considered and the game was improved.

Game distribution: Once the teacher was satisfied and the game was approved, the game was ready to be distributed to the students in the class.

\section{CASE STUDY}

The goal of the research study was to investigate learner experience when the Final Frontier game was used in the class to teach scientific knowledge of the 
planets from the Solar system to primary school children.

This section presents the evaluation methodology applied, case study set-up and results analysis for of the collected data.

\subsection{Research Methodology}

The evaluation included a group of children who were taught by using the Final Frontier game. The learning activity took place in class, during the normal hours of study. A total of 53 children of age 9-10 years from Saint Patrick Boys National School located in Dublin, Ireland took part in the case study. Team members from the National College of Ireland and Dublin City University (DCU) have prepared and helped perform the tests.

The evaluation meets all Ethics requirements. Prior to running the case study, the Ethics approval was obtained from the DCU Ethics Committee and all required forms were provided to the children and their parents, including informed consent form, informed assent form, plain language statement and data management plan. These documents include a detailed description of the testing scenario, as well as information on study purpose, data processing and analysis, participant identity protection, etc.

The flow of the evaluation is illustrated in Figure 7 that presents in details the steps followed by the researchers. It can be seen that prior to beginning the evaluation, the consent forms signed by parents were collected. Then the children were introduced to the research case study and asked to review and sign the assent form. The children had roughly 20 minutes to play the game or till they finished the game before doing a survey.

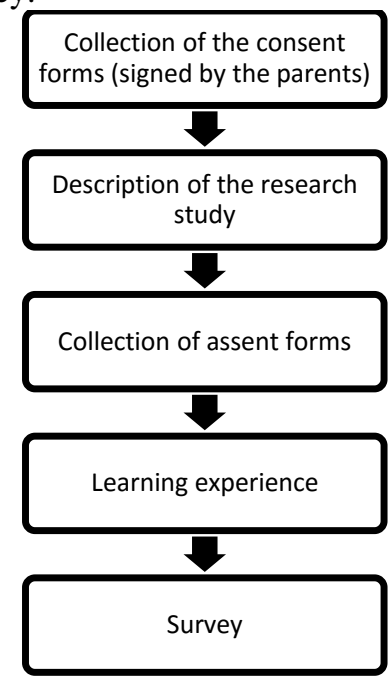

Figure 7: Evaluation process.
Table 2: Survey questions.

\begin{tabular}{|c|c|}
\hline Question & Answer/Scale \\
\hline $\begin{array}{l}\text { Q1. The video game } \\
\text { helped me to better } \\
\text { understand the } \\
\text { characteristics of different } \\
\text { planets. }\end{array}$ & $\begin{array}{c}\text { - Strongly Disagree } \\
\text { - Disagree } \\
\text { - Neutral } \\
\text { - Agree } \\
\text { - Strongly Agree }\end{array}$ \\
\hline $\begin{array}{l}\text { Q2. The video game } \\
\text { helped me to learn easier } \\
\text { about planets. }\end{array}$ & $\begin{array}{l}\text { - Strongly Disagree } \\
\text { - Disagree } \\
\text { - Neutral } \\
\text { - Agree } \\
\text { - Strongly Agree } \\
\end{array}$ \\
\hline $\begin{array}{l}\text { Q3. I enjoyed this lesson } \\
\text { that included the video } \\
\text { game on planets. }\end{array}$ & $\begin{array}{l}\text { - Strongly Disagree } \\
\text { - Disagree } \\
\text { - Neutral } \\
\text { - Agree } \\
\text { - Strongly Agree }\end{array}$ \\
\hline $\begin{array}{l}\text { Q4. The quizzes that I did } \\
\text { in the game helped me } \\
\text { better remember what I } \\
\text { learned. }\end{array}$ & $\begin{array}{c}\text { - Strongly Disagree } \\
\text { - Disagree } \\
\text { - Neutral } \\
\text { - Agree } \\
\text { - Strongly Agree }\end{array}$ \\
\hline $\begin{array}{l}\text { Q5. The video game } \\
\text { distracted me from } \\
\text { learning. }\end{array}$ & $\begin{array}{c}\text { - Strongly Disagree } \\
\text { - Disagree } \\
\text { - Neutral } \\
\text { - Agree } \\
\text { - Strongly Agree }\end{array}$ \\
\hline $\begin{array}{l}\text { Q6. I would like to have } \\
\text { more lessons that include } \\
\text { video games. }\end{array}$ & $\begin{array}{c}\text { - Strongly Disagree } \\
\text { - Disagree } \\
\text { - Neutral } \\
\text { - Agree } \\
\text { - Strongly Agree }\end{array}$ \\
\hline $\begin{array}{l}\text { Q7. What did you like } \\
\text { most about the game? }\end{array}$ & $\begin{array}{l}\text { Students to provide } \\
\text { their feelings toward the } \\
\text { experience }\end{array}$ \\
\hline $\begin{array}{c}\text { Q8. Comments / } \\
\text { Suggestions (optional) }\end{array}$ & $\begin{array}{l}\text { Students to provide } \\
\text { their comment if they } \\
\text { wished }\end{array}$ \\
\hline $\begin{array}{l}\text { Q9. What way of learning } \\
\text { you would like (tick one } \\
\text { answer)? }\end{array}$ & $\begin{array}{l}\text { - Teacher based learning } \\
\text { - Computer game based } \\
\text { learning }\end{array}$ \\
\hline
\end{tabular}

The case study investigated the learner experience with the game and the game usability. A learner satisfaction questionnaire assessing student level of experience and game usability was collected. Standard emojis were associated with each answer to the questionnaire's questions.

\subsection{Results Analysis}

\subsubsection{Learner Experience}

Learner experience in using the Final Frontier game was investigated and evaluated by questions Q1 to Q6 in the survey. The experience was analysed in terms 
Table 3: Children answers on the user experience survey.

\begin{tabular}{|c|c|c|c|c|c|}
\hline & SD & D & N & A & SA \\
\hline Q1 & 0 & 0 & $7.5 \%$ & $60.5 \%$ & $32 \%$ \\
\hline Q2 & 0 & 0 & $11.2 \%$ & $45.4 \%$ & $43.4 \%$ \\
\hline Q3 & 0 & 0 & $1.9 \%$ & $19.1 \%$ & $79 \%$ \\
\hline Q4 & 0 & $1.9 \%$ & $13.2 \%$ & $52.9 \%$ & $32 \%$ \\
\hline Q5 & $45.4 \%$ & $24.7 \%$ & $15 \%$ & $3.7 \%$ & $11.2 \%$ \\
\hline Q6 & $1.9 \%$ & 0 & $1.9 \%$ & $7.5 \%$ & $88.7 \%$ \\
\hline
\end{tabular}

of number of Strongly Agree / Agree answers for Q1, Q2, Q3, Q4, and Q6 and Strongly Disagree / Disagree for Q5.

The overall learner experience of children was excellent (see Table 3). 92.5\% of children confirmed that the video game helped them to better understand the characteristics of the two planets. $88.8 \%$ of children thought that the video game helped them to learn easier about planets. $98.1 \%$ of students enjoyed the lesson that included the video game. $84.9 \%$ of children agreed on the fact that quizzes embedded in the game helped them better remember what they have learned. $70.1 \%$ of children disagreed that the video game distracted them from learning. $96.2 \%$ of children expressed that they would like to have more lessons that include video games.

Note that for clarity reasons, in Table 3, SD refers to Strongly Disagree, D refers to Disagree, N refers to Neutral, A refers to Agree, and SA refers to Strongly Agree.

\subsubsection{Game Usability}

The game usability of the Final Frontier was also analysed through Q7, Q8 and Q9 from the survey.

An analysis of the answers provided for Q7 and Q8 shows that $92.6 \%$ of children mentioned that they have enjoyed the game, in particular the fun aspect, learning aspects, stars and meteorites collection, avatar, use of jetpack, and interactive puzzle room.

Regarding Q9, 94\% of children mentioned that they prefer computer game-based learning during the normal teaching class, which is an outstanding result for the deployment of this game.

\section{CONCLUSIONS}

This study addresses the problem of motivating, engaging, and improving learning experience of students in the STEM field. A novel 3D interactive video game (Final Frontier) was designed and tested with children from a Dublin-based primary school. The game supports knowledge acquisition about two
Solar system planets: Mercury and Venus through direct experience, active recall, challenges and fun.

The game design methodology of Final Frontier was described in this paper. An analysis of the results collected in a case study conducted on a group of 57 students was also presented in the paper. Learner experience with the game, and game usability were investigated through a survey. An analysis of the survey questionnaire results shows that a large majority of children were satisfied with the game usability: $92.6 \%$ of children enjoyed the game. The survey also shows that children have appreciated various game features including the fun aspect, learning aspects, stars and meteorites collection, avatar, use of jetpacks, and interactive puzzle room that existed in the game.

The overall learner experience of children was excellent, $92.5 \%$ of children confirmed that the game helped them to learn better about the two planets.

Future work will aim to expand the research study on the Final Frontier game as well as on the game methodology. Further research will include all planets of the Solar system to the game. The learning impact of the game will also be assessed.

Research has shown the benefits of integrating adaptation based on learner quality of experience and learner profile in the learning process (Muntean et al. 2006, Muntean et al. 2010b).

Thus, the adaptive feature will also be designed and developed in the game in order to address the problem of learners' diversity, their difference in terms of prior knowledge and learning experience.

The Final Frontier 3D interactive computer game introduced in this paper will be deployed through the NEWTON platform (NEWTON 2016) and tested in different European primary schools. Case studies that will investigate the benefits of the educational game in different European schools will be organized and an analysis of the results across countries will be performed.

\section{ACKNOWLEDGEMENTS}

This research is supported by the NEWTON project (http://www.newtonproject.eu/) funded under the European Union's Horizon 2020 Research and Innovation programme, Grant Agreement no.688503.

\section{REFERENCES}

Boyle, E., Connolly, T. M., \& Hainey, T. (2011). The role of psychology in understanding the impact of computer 
games. Entertainment Computing, 2(2), 69-74. https://doi.org/10.1016/j.entcom.2010.12.002

Erhel, S., \& Jamet, E. (2013). Digital game-based learning: Impact of instructions and feedback on motivation and learning effectiveness. Computers \& Education, 67(Supplement $\quad$ C), 156-167. https://doi.org/10.1016/j.compedu.2013.02.019

Ghergulescu, I., \& Muntean, C. H. (2012). Measurement and Analysis of Learner's Motivation in Game-Based E-Learning. In D. Ifenthaler, D. Eseryel, \& X. Ge (Eds.), Assessment in Game-Based Learning (pp. 355378). New York, NY: Springer New York. Retrieved from http://link.springer.com/chapter/10.1007/978-14614-3546-4_18?null

Ghergulescu, I., \& Muntean, C. H. (2010a). Assessment of motivation in games based e-learninf. IADIS International Conference Cognition and Exploratory Learning in Digital Age (CELDA 2010), Timisoara, Romania, pp.71-78

Ghergulescu, I., \& Muntean, C. H. (2010b) "MoGAME: Motivation based Game Level Adaptation Mechanism", in the 10th Annual Irish Learning Technology Association Conference (EdTech 2010) Athlone, Ireland http://www.ilta.net/files/EdTech2010/R2_Ghergulescu Muntean.pdf

Ghergulescu, I., \& Muntean, C. H (2016). ToTCompute: A Novel EEG-based TimeOnTask Thresholds Computation Mechanism for Engagement Modelling and Monitoring, International Journal of Artificial Intelligence in Education, Special issue on 'User Modelling to Support Personalization in Enhanced Educational Setting, pp 1-34, April 2016

Hainey, T., Connolly, T. M., Boyle, E. A., Wilson, A., \& Razak, A. (2016). A systematic literature review of games-based learning empirical evidence in primary education. Computers \& Education, 102(Supplement C), https://doi.org/10.1016/j.compedu.2016.09.001

Jabbar, A. I. A., \& Felicia, P. (2015). Gameplay Engagement and Learning in Game-Based Learning A Systematic Review. Review of Educational Research, $85(4)$, 740-779. https://doi.org/10.3102/0034654315577210

Le Brocq, A. (2017). Ice Flows: A Game-based Learning approach to Science Communication (Vol. 19, p. 19075). Presented at the EGU General Assembly Conference Abstracts. Retrieved from http://adsabs.harvard.edu/abs/2017EGUGA..1919075 $\mathrm{L}$

Doran, L. (2016). Games, Videos Continue to Make Big Gains in Classrooms, Survey Finds. Education Week Digital Education. May 12.

Li, M.-C., \& Tsai, C.-C. (2013). Game-Based Learning in Science Education: A Review of Relevant Research. Journal of Science Education and Technology, 22(6), 877-898. https://doi.org/10.1007/s10956-013-9436-x
Marfisi-Schottman I., George S., Tarpin-Bernard F. (2010) Tools and Methods for Efficiently Designing Serious Games. Proceedings of 4th Europeen Conference on Games Based Learning, Copenhagen, Denmark, p. 226-234.

Muntean C.H, Andrews, J. (2017), Final Frontier: An Educational Game on Solar System Concepts Acquisition for Primary Schools, 17th IEEE International Conference on Advanced ( ICALT), Timisoara, Romania

Muntean C.H., McManis, J. (2006). End-user Quality of Experience oriented adaptive e-learning system.

Journal of Digital Information, Vol. 7, No. 1

NEWTON (2016), "H2020: Networked Labs for Training in Sciences and Technologies for Information and Communication," 2016. [Online]. Available: http://www.newtonproject.eu/.

Peña, J. G. V., \& Tobias, G. P. A. R. (2014). Space Rift: An Oculus Rift Solar System Exploration Game. Philippine Information Technology Journal, 7(1), 5560.

Ravipati (2017). Trends: STEM Game-based Learning to See Surge in Immersive Tech. The Journal, August 2017.https://thejournal.com/articles/2017/08/29/trends -game-based-learning-market-to-see-surge-inimmersive-tech.aspx

Qian, M., \& Clark, K. R. (2016). Game-based Learning and 21st century skills: A review of recent research. Computers in Human Behavior, 63, 50-58. https://doi.org/10.1016/j.chb.2016.05.023

Sin, Z. P. T., Ng, P. H. F., Shiu, S. C. K., \& Chung, F. 1. (2017). Planetary marching cubes for STEM sandbox game-based learning: Enhancing student interest and performance with simulation realism planet simulating sandbox. In 2017 IEEE Global Engineering Education Conference (EDUCON) (pp. 1644-1653). https://doi.org/10.1109/EDUCON.2017.7943069

Spitz, H.H., Consolidating facts into the schematized learning and memory system of educable retardates, dans N.R. Ellis (éd.), International review of research in mental retardation, vol. 6, New-York: Academic Press, 1973.

Sung, H.-Y., \& Hwang, G.-J. (2013). A collaborative gamebased learning approach to improving students' learning performance in science courses. Computers \& Education, 63(Supplement C), 43-51. https://doi.org/10.1016/j.compedu.2012.11.019

TechNavio (2017). Global K-12 Game-based Learning Market 2017-2021, August 2017, https://www.researchandmarkets.com/research/h6m4w j/global_k12

Tobias, S., Fletcher, J. D., \& Wind, A. P. (2014). GameBased Learning. In Handbook of Research on Educational Communications and Technology (pp. 485-503). Springer, New York, NY. https://doi.org/10.1007/978-1-4614-3185-5_38 
Wu, W.-H., Hsiao, H.-C., Wu, P.-L., Lin, C.-H., \& Huang, S.-H. (2012). Investigating the learning-theory foundations of game-based learning: a meta-analysis. Journal of Computer Assisted Learning, 28(3), 265279. https://doi.org/10.1111/j.1365-2729.2011.00437.x 